\title{
In Terms of Music Teachers, the Evaluation of Music Types in the Curriculum for Music in Secondary Education in Turkey
}

\author{
Gülnihal GÜL \\ Uludag University \\ gulnihal@uludag.edu.tr
}

\begin{abstract}
Along with the establishment of the Republic, a song repertoire consisting of transferred songs was previously endeavoured to be formed by taking school music samples of foreign countries and writing Turkish words below them. Afterwards, with the same percept, an imitation songs repertoire was attempted to be formed by our composers. Since the 1950s, the idea that school music should be on the axis of folk music and that music education should be carried out through school music samples composed from the close environment of the child has begun to take place. Together with the various developments since the 1970s, the tendency towards soft music has strengthened in society and also interest in Turkish classical music has increased. Moreover, since the 1970s, soft and classical music samples have begun to be used in music education, which was built on folk music in 1968. Thus, high school music teaching programs which went into effect in 1986 were prepared accordingly.

Today, the sense that bringing to the classroom appropriate samples of vital music types in society, getting the student to learn at least one example of each music type and introducing these types is dominating. In this study, music types in middle school music teaching programs in Turkey were endeavoured to be evaluated in terms of music teachers. The subject was researched with the case study method which is one of the qualitative research methods. The oriented exemplification method was used in the study and 5 music teachers working in a middle school participated in the study group. The data was analysed by forming the necessary coding and themes. According to the obtained findings, results and suggestions were given place.
\end{abstract}

Keywords: Music Education, Music Types, Music Teaching Programs, Middle School

\section{Introduction}

Important developments have been made in music education together with the education revolution initiated by the leadership of Atatürk after the announcement of the republic (1923). Within this context, music lessons have started to be compulsory in primary and middle schools (Gül \& Bozkaya, 2010).

It is seen that since 1924, music education is carried out from the music concept and theory related to tones, and upon this understanding, the education given at Music Teacher School training music educators was built with the effect of trying to place international art music conception. in the following years, the view arose that the Turkish Music Education System should be organised by having its resource based upon school songs from Turkish Folk Music. Within this context, this thought is enhanced with the view of Paul Hindemith(1895-1963) who prepared a report during the establishment of Ankara State Conservatoire (1936) and said, "....The song repertoire of music lessons in schools should be taken from the magnificent, rich repertoire of the former and strong Turkish Folk Music" (Gedikli, 1999). However, in those years, it is seen that it took time for Turkish Folk Music to be in the repertoire of educational music as it could not find a place extensively at a national level within the widespread music types and carried on as the music of the countryside.

Beginning from the 1950s and together with the 1960s, the concept that school music samples should set out from the child him or herself and his/her close environment and be on the axis of folk music became important (Dinçer, 1988). Furthermore, nursery rhymes and various folk songs were started to be given place extensively in music education (Dinçer, 1988). in this context, significant changes happened in Turkish school music in the 1968 program; school music education entered the process of configuration by being based upon folk music and it took its place in the program (Bozkaya, 2001).

Different developments have begun to take place since the 1970s. While the tendency in the society towards popular music was enhancing, the Ministry of National Education prepared high school popular music competitions. Moreover, the interest in Turkish Classical Music became stronger. Thus, the program in the new curriculum for secondary education which was put into effect in 1987(1986) was prepared in accordance with this statement: "Getting the student to sufficiently comprehend the technical features and values of our national music which is a whole with its classical and folkloric types so that he/she can be an active member of his/her society and introducing this art practically" (Çevik, 1989). 
ISSN 2411-9563 (Print) ISSN 2312-8429 (Online)
European Journal of Social Sciences Education and Research
September-December 2014

Volume 1, Issue 2

Along with these developments, in the society, the idea of bringing suitable samples of music types to the classroom became widespread. To study this subject and to reach scientific results, a symposium about "The Place of Music Types in Education" was organised at Fatih Education Faculty in Karadeniz Technical University on 26-28 April 1993 (KTÜ, 1993).

An important change occurred in the Turkish Education System in 1994; by having it raised to 8 years, compulsory education was evaluated within the scope of primary education. According to this, with the Board of Education and Discipline of the Ministry of National Education Decision No. 298 dated 22.04.1994, the Curriculum for Music Lessons in Primary Schools, which has been accepted according to be tried out and developed since the academic year 1995-1996, was also re-organized by being divided into 3 periods as 1st, 2nd, 3rd grades, 4th, 5th grades and 6th, 7th and 8th grades. It could be said that the program is an example for a work in terms of the technique used in the preparation of a program. The opinion, "As well as with the obtainment of a shared music repertoire it requires, the common, primary music culture which gives place to the principal music types vital in our country and which preserves, reinforces and develops our national unity and solidarity has been essentially taken" was given place in the information related to school music education in the general explanations part of the program (MEB,1994). Thus, the idea that all the music types vital in our country should be in the program was obtained after long searches (MEB,1994).

In 2006, towards the general aim and principles of the Turkish National Education, the preparation of a music repertoire which gives place to local, regional, national and international music types and which also has music types reinforcing our national unity and solidarity as well as facilitating our integration with the world was essentially taken in the curriculum for music lessons that was prepared and applied with a constructivist approach (MEB, 2006).

When the article related to the field is analysed, the following are observed: Firstly, a study made by Göner (2006) reveals that songs are appropriate for the age of children, more place is given for contemporary songs but there is a need to increase the number of songs and folk songs in music course books in primary schools. Secondly, the students of Varış and Cesur (2012) are generally interested in popular music activities and not in classical music activities. Also, the content of the music lesson does not motivate students to listen to different music types. Thirdly, samples of education music and Turkish Folk Music are mostly allowed for in the teachers books of Gün Duru(2013), but having examples of Turkish Folk Music related to all areas in these books is useful in terms of putting forward our musical variety. Finally, Köroğlu (2014) reached the conclusion that songs students enjoy singing and contemporary songs which appeal to children and which are appropriate for the developing and changing conditions of society could be added to the curriculum for music lessons.

In this study, starting from the idea that art is a universal language and that it is not just an important component of a national culture but also of an international one, the current situation of curriculum for music lessons in secondary education was researched in terms of music types as well as with what the possible developments may be in the future. This was also endeavoured to be put forward with data regarding the opinions of music teachers.

Related to music types given place in the curriculum for music, the purpose of the research is to specify the opinions of music teachers working in junior high schools. Regarding this purpose, the subproblems below have been specified:

1. What are the views of teachers related to which music types should be allowed for in music timetables in secondary education?

2. What are the views of teachers related to how adequate music types in music programs in secondary education are in having the aims and objectives achieved in education?

3. In terms of tune structure and the meaning of words of music types in the repertoire of music programs in secondary education, what are the views of teachers related to their feature of having suitability for the class level?

4. What are the views of teachers related to the students' interest in the types of music in lessons?

5. With regard to the practices of music education, what are the preferences of directors related to music types and what are the views of music teachers related to the requests of the directors in this aspect?

\section{Method}

Research model, study group and information about the collection and analysis of data are included in this section.

Research Model 
This study is a qualitative case study which is directed towards the evaluation of music types in the curriculum for music in Turkey's secondary education in terms of music teachers. The most essential feature of the qualitative case study is researching one or more cases thoroughly (Yıldırım \& Şimşek, 2006).

\section{Study Group}

Typical case illustration which is one of the oriented illustration methods was used in the research. Oriented illustration methods are useful in discovering and explaining facts and cases in many situations. The purpose of typical case illustration is forming an opinion about a specific field by working on normal situations and then the aim is informing those who do not have knowledge about this field, topic, practise or novelty (Yıldırım ve Şimşek, 2006). Through this illustration, it will possible to have an idea about the opinions of music teachers related to music types in the curriculum for music in Turkey's secondary education. This illustration group was formed by 5 music teachers working in junior high schools and who participated voluntarily in the research.

\section{The Collection of Data}

A semi-structured interview form prepared by the researcher was used for the collection of data in the research. Questions are previously specified in semi-structured interviews and data is collected with the questions (Karasar, 1999). First of all, a literature review was made when the questions were being prepared and the effect of music types in the curriculum for music in junior high schools was focused on during the process and duration of music lessons. A semi-structured interview form was prepared by turning fundamental topics into themes. At the end of this process, a trial interview was carried out. Through the prepared interview form, meetings took place with the participants.

\section{The Analysis of Data}

In the research, the opinions of the participants were taken in writing on the semi-structured interview forms. A number was given to the interview papers. The data obtained from the research was organized into significant sections by the researcher, and these sections were encoded. These formed codes were used in the analysis and organization of data.

\section{Findings}

Themes and according to these themes, codes and sub codes were specified by the researcher as the result of the analysis of the responses the participants gave to the interview questions. Findings related to the specified codes and sub codes have been analysed below.

The Opinions of Teachers Related to Music Types Needed to be Given Place in the Curriculum for Music in Junior High Schools

The music teachers who participated in the interview believe that the music types in the curriculum are appropriate but they also consider the necessity of a program consisting of outstanding classical music samples that will develop the admiration of students and appeal to them and which also includes works of the specific representatives in jazz music and selected samples from our traditional music.

"I think the types in the program are appropriate. However, the most known samples of classical music should be given place and through this, polyphonic music should be tried to be made loveable." (P.1)1

"I have observed that students are not aware of nearly all the music types except the ordinary samples of current popular music. At this point, I think outstanding samples of classical music works, works of specific representatives in jazz music and samples of our folk and classical music at the appropriate level of students' appreciation should be included in the program in order to broaden the horizon of our students in terms of music types." (P.2)

"I think all music types should be allowed for in general terms without details." (P.4)

"I think the types in the program are appropriate." (P.5)

1 P: Participant 
The Opinions of Teachers Related to the Adequacy of Music Types in the Curriculum for Music in Junior High Schools in Accomplishing Education Aims and Achievements

Music teachers who participated in the interview specified that they had difficulty in accomplishing the education aims and achievements of music types in the program due to meeting the students for a period once a week. Also, it has been specified that students do not willingly study the samples of Turkish Classical Music and therefore, in this music type, difficulty is experienced in the obtainment of aims and achievements.

"We meet the students for an hour once a week. Therefore, I cannot completely accomplish the aims and achievements."(P.1)

"I could never get the children to love Turkish Classical Music. Therefore, I cannot accomplish the aims and achievements relating to this type. I can highly ensure the aims and achievements of samples in Turkish Folk Music and current popular music." (P.3)

"We have a lesson with the students for an hour once a week. Therefore, as a solution, I give an assignment to the students beforehand about the topic in order to accomplish the aims and achievements. Later on, I reach the aims and achievements when I reinforce with song samples relating to the music types, and through this, I think the achievements are more permanent." (P.5)

The Opinions of Teachers Related to the Suitability of Music Types (Turkish Folk Music, Turkish Classical Music, Popular Music, School Music Samples) in the Repertoire for the Class Level in terms of Tune Structure and the Meaning of Words

Music teachers who participated in the interview have specified that the sound limit and tune structure of the songs in the repertoire are generally not appropriate in terms of singing and that the tune structure of the songs are samples which would be difficult to be played with a recorder or even not be able to be played at all. They have also specified that the topics and the song samples regarding the topics are difficult for the class level.

"Most of the sound limits of the songs in the repertoire are not appropriate for children. They need to be transposed in eartraining. Most of the songs are suitable to be played with a melodica." (P.1)

"Most of them are inappropriate for the class level. According to the class level, a very easy and a very difficult song can come one after the other." (P.2)

"In terms of their tune structure and the meaning of words, the songs in the books are inappropriate for the class level. I am constantly searching for sources." (P.3)

"I think most of the samples of education music in the repertoire are inappropriate. Most of the songs are suitable to be played with only the melodica." (P.4)

"Books are inappropriate in terms of topic explanation, examples and visuals. I don't think they are prepared conscientiously. for example, the topics and songs in the 5th grade program are difficult for children who have not had a branch teacher until that time."(P.5)

Furthermore, a music teacher who participated in the research has specified that in the current auxiliary sources and books, the samples concerning school songs are inadequate.

"The school songs in the auxiliary sources and books are always the same. It is boring for both the teacher and the child."(P.4)

The Opinions of Teachers Related to the Attention of Students towards Music Types in Lessons

Music teachers who participated in the interview have stated that students are mostly interested in the samples of popular music and that they enjoy studies which have examples from this type. Also, the teachers have specified that students enjoy studying samples relating to Turkish Folk Music and easy songs with dual beats. However, it has been stated by the teachers that examples concerning Turkish Classical Music do not appeal to students.

"Children are interested in all music types. However, samples of popular music and Turkish Folk Music which are prone to their ears are played and sung by them with a greater interest. Also, they highly enjoy playing easy songs with dual beats." (P.1)

"The environment they are in has a great effect. in one district I worked in, children were interested in samples relating to Turkish Folk Music while in another district, students highly enjoyed studying examples concerning rock and popular music. I have difficulty in getting the students to be interested while studying samples from Turkish Classical Music." (P. 3) 
"They are generally interested in current popular songs and samples relating to Turkish Folk Music." (P.4)

The Preferences of Directors Related to Music Types in Practices of Music Education and the Opinions of Teachers about the Directors' Requests

Four music teachers who participated in the research have stated that in their preferences regarding music types they face the restraint of the directors and therefore, they do not adequately feel themselves independent. It is observed that directors particularly prefer practices of music education which have traditional music, request practices from teachers that have music types they listen to and know about and that they do not support studies of various types. Besides this, one participant who specified that his/her work is supported by the school principal said that he/she carries out successful work and that his/her success is greatly affected by the support of the director.

"Directors want mostly samples relating to Turkish Folk Music and Turkish Classical Music to be in the practices of music education. They do not encourage music types they don't listen to or don't know about. in concerts especially in which there are samples from polyphonic music type, directors become disappointed by thinking there is a disorder and something is not going right. Therefore, selections directed towards types which the directors can understand have to be made when there is a school night or a concert."(P.1)

"I face the oppressive attitude of the school administration in the selection of types and works when there is any kind of musical activity at school. All the samples which will be in concerts have to firstly be approved by the administration. Therefore, I believe that I am certainly not independent in the practices of music education I carry out."(P.2)

"Since most of the directors are aged 45 and over, their preferences are mostly Turkish Folk Music and Turkish Classical Music. When I prepare programs with different types, I cannot make them happy."(P.3)

"My principal prefers to see works which feature traditional music."(P.4)

"In my school, the directors do not intervene in preferences about music types. On the contrary, I must say they support me. I believe that they have a great help in the successful programs I perform."(P.5)

Results and Suggestions

Regarding the findings obtained from the research, the following results have been reached:

-The music types in the curriculum for music are appropriate, but samples which will develop the admiration of the student are insufficient.

-There is difficulty in accomplishing the aims and achievements related to music types due to the tightness of periods.

- Teachers experience difficulty in accomplishing the aims and achievements directed towards the samples particularly concerning Turkish Classical Music.

-Most of the songs in the repertoire are inappropriate for the class level in terms of sound limit and tune structure.

-Most of the songs are suitable to be played with only the melodica. It is difficult to play them with the recorder or they cannot even be played with it at all.

-The current auxiliary sources and samples relating to school songs are insufficient.

-Students are mostly more interested in samples relating to popular music and Turkish Folk Music than examples from other music types, but directed towards these types, more outstanding samples which will advance the admiration of children should be allowed.

-Samples relating to Turkish Classical Music do not appeal to students and during studying, difficulties are experienced.

-Teachers face the restraint of directors mostly in the selection of music types and therefore, they cannot feel themselves independent in their work.

As part of the obtained results, the following are suggested:

-Increasing music periods in the weekly timetable.

-Reviewing and re-organising the samples relating to types in the music programs in a way that will advance the admiration of the student.

-Regarding the opinions and suggestions of music teachers working in junior high schools, re-analysing all samples concerning music types in terms of tune structure, sound limit and the meaning of words. 
-Selecting songs by taking into consideration the features of the recorder and melodica which are taught along with voice training in secondary education.

- Giving music teachers more sources which have samples of education music in order to assist in the selection of music types.

- For the purpose of using them in music lessons in secondary education, producing more education materials appropriate for the development level of children at that age-group. Organizing competitions for this and rewarding composers.

-Making an anthology by re-evaluating samples of Turkish Classical Music in a way so that they are appropriate for the development level of children and giving place to it in that way in music education in secondary schools.

-Ensuring music teachers to use more effectively explanatory music samples about international classical music which will advance the admiration of children.

- Having directors assist music teachers in the accomplishment of anticipated aims and achievements in the curriculum for music, and having them avoid personal practices which feature their own preferences.

\section{References}

[1] Bozkaya, İ. (2001). Contemporary Music Education and its Essential Features. The 2000 Symposium in Music. (pp. 225-235). Ankara: Neyir Printing.

[2] Çevik, S. (1989). Main Problems in Music Teaching. Music Teaching and its Problems in Junior High Schools. (pp. 82-86). Ankara: Set Ofset Printing.

[3] Dinçer, M. (1988). How Should Music Education Be in Pre-school Teaching, Primary Schools and Junior High Schools in Turkey? First Music Congress Notifications. (pp. 445-454). Ankara: Evren Ofset

[4] Gedikli, N. (1999). Hindemith and the Main Problems of Turkish Music Education. International Art Music with its Effect and Results in Music. (pp. 79-88). İzmir: Ege University Printing House.

[5] Göher, F.M. (2006). The Functionality in Practice of Course Books in Primary School. (ed. Atak Yayla, A. and Yayla,F.) National Music Education Symposium. ( pp. 241-247).Denizli: Anı Publishing.

[6] Gün Duru, E. (2013). The Reflections of Turkish Music Culture on General Music Education. International Journal of Social Science, Volume 6, Issue 5,(pp. 587-596).

I. National Music Education Symposium Notifications. (1993). The Place of Music Types in Education. Karadeniz Technical University Fatih Education Faculty. Trabzon.

[7] Karasar, N. (1999). Scientific Research Method, Concepts, Principles, Techniques. Ankara: Nobel Publishing.

[8] Köroğlu, N. (2014). Regarding the 2006 Curriculum for Music, the Opinions of Music Teachers in the Secondary Stage of Primary Education. Art Education Journal, Volume 2, Issue 1, (pp.127-141).

[9] Ministry of National Education. (MEB). (1994). The Curriculum for Music in Primary Schools. Ankara: National Education Printing House.

[10] Ministry of National Education. (MEB). (2006). The Curriculum for Music in Primary Education (1st-8th Grades) Ankara.

[11] Varış, A. ve Cesur, D. 2012. The Opinions of Teachers Related to the Functionality of Music Lessons in Junior High Schools. International Journal of Social Science, Volume 5, Issue 7, (pp. 751-768).

[12] Yıldıım, A. \& Şimşek, H. (2006). Qualitative Research Methods in Social Sciences. Ankara: Seçkin Publishing. 